ARTICLE

DOI: $10.1038 / s 41467-018-06317-8$

\title{
Gas-solid reaction based over one-micrometer thick stable perovskite films for efficient solar cells and modules
}

\author{
Zonghao Liu', Longbin Qiu', Emilio J. Juarez-Perez (10) 1, Zafer Hawash (10 1, Taehoon Kim (1) 1, Yan Jiang (1) 1, \\ Zhifang Wu', Sonia R. Raga', Luis K. Ono', Shengzhong (Frank) Liu' ${ }^{2,3}$ \& Yabing Qi iD ${ }^{1}$
}

Besides high efficiency, the stability and reproducibility of perovskite solar cells (PSCs) are also key for their commercialization. Herein, we report a simple perovskite formation method to fabricate perovskite films with thickness over $1 \mu \mathrm{m}$ in ambient condition on the basis of the fast gas-solid reaction of chlorine-incorporated hydrogen lead triiodide and methylamine gas. The resultant thick and smooth chlorine-incorporated perovskite films exhibit full coverage, improved crystallinity, low surface roughness and low thickness variation. The resultant PSCs achieve an average power conversion efficiency of $19.1 \pm 0.4 \%$ with good reproducibility. Meanwhile, this method enables an active area efficiency of $15.3 \%$ for $5 \mathrm{~cm} \times$ $5 \mathrm{~cm}$ solar modules. The un-encapsulated PSCs exhibit an excellent $\mathrm{T}_{80}$ lifetime exceeding $1600 \mathrm{~h}$ under continuous operation conditions in dry nitrogen environment.

\footnotetext{
${ }^{1}$ Energy Materials and Surface Sciences Unit (EMSSU), Okinawa Institute of Science and Technology Graduate University (OIST), 1919-1 Tancha, Onna-son, Kunigami-gun, Okinawa 904-0495, Japan. ${ }^{2}$ Key Laboratory of Applied Surface and Colloid Chemistry, Ministry of Education, Shaanxi Key Laboratory for Advanced Energy Devices, Shaanxi Engineering Lab for Advanced Energy Technology, School of Materials Science and Engineering, Shaanxi Normal University, 710119 Xi'an, China. ${ }^{3}$ Dalian National Laboratory for Clean Energy, iChEM, Dalian Institute of Chemical Physics, Chinese Academy of Sciences, 457 Zhongshan Road, 116023 Dalian, China. Correspondence and requests for materials should be addressed to Y.Q. (email: Yabing.Qi@OIST.jp)
} 
O rganic-inorganic lead halide perovskite solar cells (PSCs) have drawn a great deal of attention in the photovoltaic research community due to their high efficiency and simple manufacturing process ${ }^{1-5}$. The power conversion efficiency (PCE) of PSCs has reached over $22 \%{ }^{6}$. Similar to other kinds of thin film photovoltaics, film qualities of perovskite layers can heavily influence device performance of PSCs. Thus, a delicate control of film quality of perovskite layers is key to achieving both superior performance and high reproducibility. Many solution processable perovskite formation methods have been developed to fabricate high-quality perovskite films, such as onestep method ${ }^{2,7-9}$ and two-step method ${ }^{10}$. These methods usually involve a transformation of $2 \mathrm{D}$ lead halide inorganic framework to the $3 \mathrm{D}$ perovskite structure. This structure transformation is often accompanied with the formation of morphological defects and crystallographic structure dislocation within the grain and at grain boundaries, where defects are present as trap states causing serious charge recombination and limiting the charge carrier diffusion length (less than $1 \mu \mathrm{m})^{11,12}$. To ensure efficient charge collection in the presence of defects, perovskite films are usually made sufficiently thin. So far, high efficiency PSCs mainly adopt perovskite films with thickness ranging from 400 to $800 \mathrm{~nm}$ (Supplementary Table 1). The low thickness fluctuation tolerance and morphological defects of thin perovskite films decrease reproducibility of the fabrication process. Moreover, thin films are prone to thickness variations and pinhole defects, which increase significantly with the area.

It is obvious that thicker perovskite films are likely to reduce the risk of forming voids and pinholes due to the larger thickness fluctuation tolerance. A high-quality thick perovskite film is desirable to achieve a high device yield and reproducibility in making large-area solar modules. Besides, thicker perovskite films can not only improve the light harvesting ${ }^{13,14}$, but also broaden light response region by utilizing the below-band absorption ${ }^{15}$. As such, it is advantageous to construct a high-quality thick perovskite film with enough carrier diffusion length in PSCs to endorse both higher efficiency and manufacturing viability. However, thick perovskite films over $1 \mu \mathrm{m}$ have been found to be generally less efficient than thin-films devices due to the poor mobility, limited carrier diffusion length and are seldom explored (Supplementary Table 1). Moreover, conventional perovskite formation methods are usually not suitable for fabricating largearea high-quality thick perovskite films. Thus, improving the quality of thick perovskite films is critical to balance the thickness and efficiency. Also, the development of new perovskite formation techniques is desirable to construct high-quality and thick perovskite films.

Recently, a perovskite formation process based on methylamine $\left(\mathrm{CH}_{3} \mathrm{NH}_{2}\right)$ gas-solid reaction has been developed to prepare highquality $\mathrm{CH}_{3} \mathrm{NH}_{3} \mathrm{PbX}_{3}(\mathrm{X}=\mathrm{I}, \mathrm{Br}, \mathrm{Cl})$, mixed halides $\mathrm{CH}_{3} \mathrm{NH}_{3}{ }^{+}$based perovskite and Cesium $/ \mathrm{CH}_{3} \mathrm{NH}_{3}{ }^{+}$mixed cations perovskite films ${ }^{16-18}$. This gas-solid reaction-based method introduces a liquid intermediate, which leads to induced morphology reconstruction, defects healing ${ }^{19,20}$. Meanwhile, $\mathrm{CH}_{3} \mathrm{NH}_{2}$ gas treatment can help reduce the defect density in perovskite films ${ }^{19,20}$ and also elimination of $\mathrm{I}_{2}{ }^{13}$. Besides, $\mathrm{CH}_{3} \mathrm{NH}_{2}$-induced $\delta$ $\mathrm{NH}_{2} \mathrm{CH}=\mathrm{NH}_{2} \mathrm{PbI}_{3}$ in $\left(\mathrm{CH}_{3} \mathrm{NH}_{3}\right)_{x}\left(\mathrm{NH}_{2} \mathrm{CH}=\mathrm{NH}_{2}\right)_{1-x} \mathrm{PbI}_{3}$ is also reported to passivate trap states to improve device performance ${ }^{21}$. Moreover, excess solvent is absent during this perovskite formation process, which avoids the possible detrimental effect-related residue solvent. Therefore, $\mathrm{CH}_{3} \mathrm{NH}_{2}$ gas-based processes are promising for depositing high-quality perovskite films across large area for PSC device fabrication ${ }^{22,23}$.

In terms of the synthetic techniques developed for perovskite, using chloride containing raw materials to prepare perovskite is a commonly used method ${ }^{3}$. Although the chlorine content in resultant perovskite films is usually much lower than the nominal ratio of chlorine added in the precursor solution and in some cases the chorine content in fully annealed perovskite films is below detection limit, both the optoelectronic properties and morphology can be tuned by appropriate chlorine incorporation 24,25 . The resultant carrier diffusion length improvement $^{11,12}$, defects density reduction ${ }^{26}$, optimization of film growth ${ }^{27-29}$, and charge tranport ${ }^{30,31}$ make this method effective in obtaining high-quality perovskite films. In particular, $\mathrm{CH}_{3} \mathrm{NH}_{3} \mathrm{PbI}_{3-x} \mathrm{Cl}_{x}$ (i.e., $\mathrm{CH}_{3} \mathrm{NH}_{3} \mathrm{PbI}_{3}$ incorporated with a small amount of $\mathrm{Cl}$ ) has been reported to exhibit a longer carrier diffusion length over $1 \mu \mathrm{m}$ compared with pure $\mathrm{CH}_{3} \mathrm{NH}_{3} \mathrm{PbI}_{3}$, and as a result device performance improved dramatically 11,12 .

These earlier works have inspired us to combine the $\mathrm{CH}_{3} \mathrm{NH}_{2}$ gas-based perovskite formation method and partial substitution of iodine ions by chorine ions to fabricate high quality over $1-\mu \mathrm{m}$ thick perovskite films with a sufficient charge diffusion length, which is not only beneficial for better light absorbing but also desirable for fabricating large-area solar modules with high yield and reproducibility via low-cost printing techniques ${ }^{13,32}$.

Here we report a simple perovskite formation method to fabricate over $1-\mu \mathrm{m}$-thick perovskite films based on the fast gas - solid reaction of chlorine-incorporated hydrogen lead triiodide $\left(\mathrm{HPbI}_{3}(\mathrm{Cl})\right)$ and $\mathrm{CH}_{3} \mathrm{NH}_{2}$ gas. The comprehensive characterization results reveal that with the synergistic effect of $\mathrm{CH}_{3} \mathrm{NH}_{2}$ gas and partial substitution of iodine ions by chorine ions, the resultant $\mathrm{CH}_{3} \mathrm{NH}_{3} \mathrm{PbI}_{3}(\mathrm{Cl})\left(\mathrm{MAPbI}_{3}(\mathrm{Cl})\right)$ films with a thickness over $1 \mu \mathrm{m}$ and low thickness variation exhibit excellent film quality. The resultant PSCs gave an average PCE of $19.1 \%$ and low PCE standard deviation $( \pm 0.4 \%)$, which indicates the excellent reproducibility of this method. Meanwhile, this method enables an active area PCE of $15.3 \%$ for $5 \mathrm{~cm} \times 5 \mathrm{~cm}$ solar modules. Besides, the un-encapsulated PSCs exhibit an excellent $\mathrm{T}_{80}$ lifetime exceeding $1600 \mathrm{~h}$ under continuous operation conditions in dry $\mathrm{N}_{2}$ environment. Our film stability study also offers the indepth understanding for the underlying mechanisms responsible for device stability improvement.

\section{Results}

Perovskite formation. Conventional perovskite formation methods are usually not suitable for fabricating high-quality thick perovskite thin films (Supplementary Fig. 1). Here, we developed a fast gas-solid reaction of $\mathrm{HPbI}_{3}(\mathrm{Cl})$ and $\mathrm{CH}_{3} \mathrm{NH}_{2}$ gas to prepare high-quality thick perovskite films. In this method, hydrogen lead triiodide $\left(\mathrm{HPbI}_{3}\right)$ was used as the starting material aiming at taking advantage of its fully coordinated $\left[\mathrm{PbI}_{3}\right]^{-}$structure to reduce iodide-vacancy and improve film quality (Supplementary Figs. 2, 3 $)^{33,34}$. Firstly, we tuned the thickness of perovskite films based on the $\mathrm{HPbI}_{3}-\mathrm{CH}_{3} \mathrm{NH}_{2}$ reaction ${ }^{20}$ by varying the substrate temperature (Supplementary Figs. 4, 5, 6, Supplementary Table 2 and Supplementary Note 1). As a result, perovskite films with thickness about $1.1 \mu \mathrm{m}$ are used as our benchmark for further studies. Partial substitution of iodine ions by chorine ions step depicted in Fig. 1a was achieved by reacting $\mathrm{CH}_{3} \mathrm{NH}_{3} \mathrm{Cl}$ (MACl) with $\mathrm{HPbI}_{3}$ to form $\mathrm{HPbI}_{3}(\mathrm{Cl})$. Considering that $\mathrm{MACl}$ exists in the solid state at room temperature but sublimes at elevated temperatures (higher than $100^{\circ} \mathrm{C}$ ), the introduction of $\mathrm{MACl}$ can not only achieve a small amount of substitution of iodine ions by chorine ions, but also tune the morphology of $\mathrm{HPbI}_{3}(\mathrm{Cl})$ films ${ }^{27,35}$. Top set in Fig. 1b shows the top-view scanning electron microscope $(\mathrm{SEM})$ images of $\mathrm{HPbI}_{3}(\mathrm{Cl})$ films prepared using $\mathrm{HPbI}_{3} / \mathrm{MACl}$ precursor solution with different $\mathrm{MACl}$ contents. It is found that upon increasing the $\mathrm{MACl}$ content, the size of voids between islands-like crystals in the $\mathrm{HPbI}_{3}(\mathrm{Cl})$ films gradually decreases, and the crystals gradually turn from the hexagonal 
a
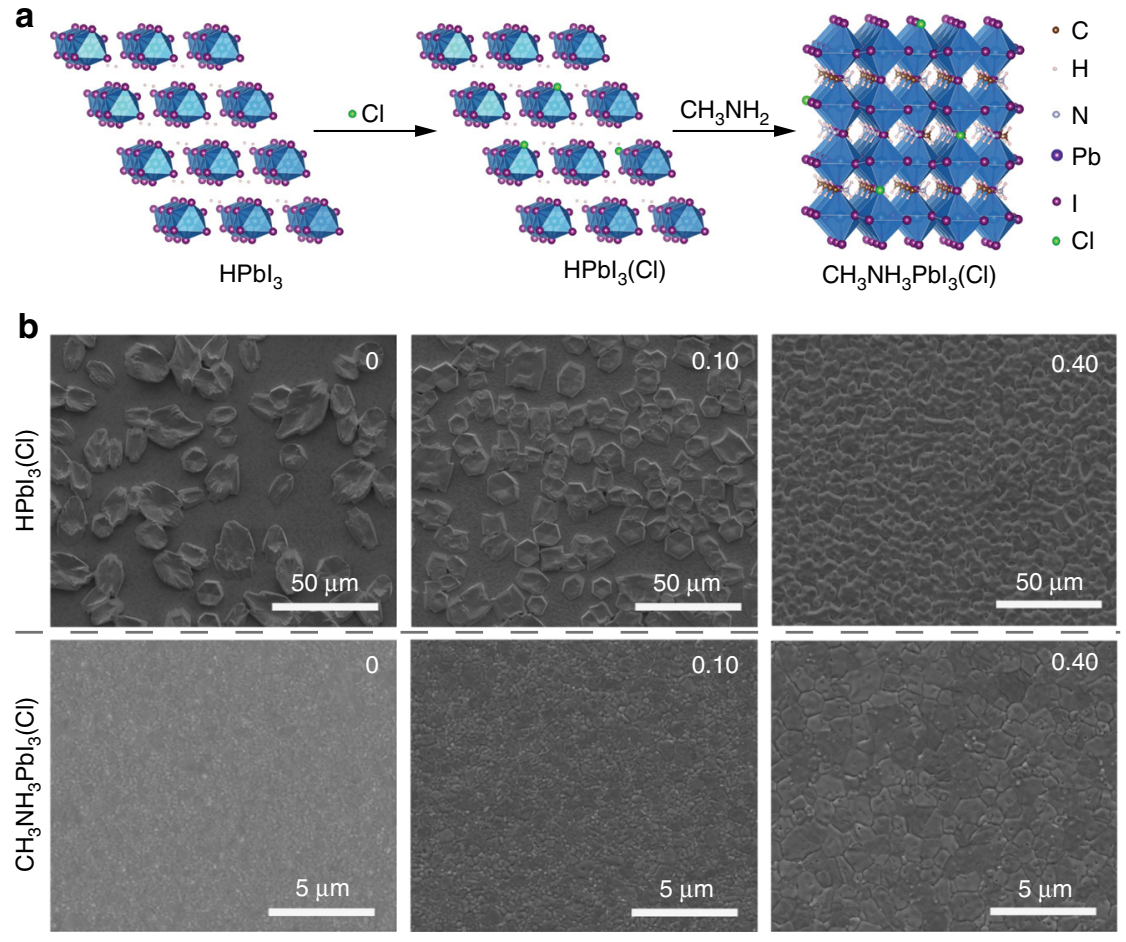

Fig. 1 Perovskite film formation. a Schematic drawing showing the reaction process of partial substitution of iodine ions by chorine ions to form chlorineincorporated perovskite $\mathrm{MAPb}_{3}(\mathrm{Cl})$ films: First, iodine ions in $\mathrm{HPbl}_{3}$ are partially substituted by chorine ions to form $\mathrm{HPbl}{ }_{3}(\mathrm{Cl})$. Then $\mathrm{HPbl}{ }_{3}(\mathrm{Cl})$ reacts with $\mathrm{CH}_{3} \mathrm{NH}_{2}$ gas to form $\mathrm{MAPbl}_{3}(\mathrm{Cl})$ via the ultra-fast acid-base reaction. b Top-view SEM images of $\mathrm{HPbl}_{3}(\mathrm{Cl}$ ) (top set, scale bar: $50 \mu \mathrm{m}$ ) and $\mathrm{MAPbl}(\mathrm{Cl}$ ) (bottom set, scale bars: $5 \mu \mathrm{m}$ ) films prepared using different molar ratios of $\mathrm{MACl}$ versus $\mathrm{HPbl}_{3}$ in the $\mathrm{HPbl}_{3} / \mathrm{MACl}$ precursor solution

shape to the square shape and then to crystals with round edges (Supplementary Fig. 7). The enhanced coverage of $\mathrm{HPbI}_{3}(\mathrm{Cl})$ films is expected to be beneficial for the subsequent $\mathrm{CH}_{3} \mathrm{NH}_{2}$ gasbased perovskite formation process.

To further investigate the incorporation of chlorine into the $\mathrm{HPbI}_{3}$, we used X-ray diffraction (XRD) spectroscopy to characterize the obtained $\mathrm{HPbI}_{3}(\mathrm{Cl})$ films. It is reported that the $\mathrm{HPbI}_{3}$ films show a hexagonal structure $20,34,36$. Upon increasing $\mathrm{MACl}$ content from 0 to 0.20 , the low-angle peak around $11.7^{\circ}$ shifts to a higher two theta value and the peak intensity increases significantly (Supplementary Fig. 8). This result suggests that the substitution of $\mathrm{I}^{-}$ion with smaller $\mathrm{Cl}^{-}$ion can shrink the crystal lattice, and $\mathrm{HPbI}_{3}(\mathrm{Cl})$ still preserves the pseudo-hexagonal phase in the case of $\mathrm{MACl}$ content lower than 0.4 . When the $\mathrm{MACl}$ content is increased to 0.40 , the XRD peak intensity of the $\mathrm{HPbI}_{3}(\mathrm{Cl})$ film at around $11.7^{\circ}$ reduced substantially. This observation suggests that when the $\mathrm{MACl}$ content is too high, the crystal structure of $\mathrm{HPbl}_{3}(\mathrm{Cl})$ cannot maintain the previous structure, which is also supported by the observed shape difference of crystal islands by SEM (Supplementary Fig. 7). This is because the large difference between the ionic radii of $\mathrm{I}^{-}$and $\mathrm{Cl}^{-}$makes the crystal structure unstable when the content of chlorine is too high. Such a phenomenon has also been observed in $\mathrm{MAPbI}_{3-x} \mathrm{Cl}_{x}$. When a small amount of $\mathrm{Cl}$ was incorporated, $\mathrm{MAPbI}_{3-x} \mathrm{Cl}_{x}$ can still maintain the pseudo-cubic phase ${ }^{11,12}$. However, a continuous solid phase of $\mathrm{MAPbI}_{3-x} \mathrm{Cl}_{x}$ theoretically cannot form at a high chlorine content due to the large size mismatch between chloride and iodide ${ }^{30}$. Besides, a slight splitting of the XRD peaks around $11.7^{\circ}$ and the formation of $\mathrm{MAPbI}_{3}$ are observed for high $\mathrm{MACl}$ content of 0.70 and 1.00 cases. The former observation may be due to the incomplete removal of $\mathrm{MACl}$ or phase separation of $\mathrm{HPbl}_{3}(\mathrm{Cl})$, and the latter observation suggests that the reaction of $\mathrm{MACl}$ with $\mathrm{HPbI}_{3}$ can form $\mathrm{MAPbI}_{3}$. The nonvisible perovskite peaks in $\mathrm{HPbI}_{3}(\mathrm{Cl})$ films at low $\mathrm{MACl}$ content from 0.05 to 0.40 may be due to the low amount of $\mathrm{MAPbI}_{3}$ seeds and detection limit of XRD. Here, we can deduce that the possible reaction for the formation of $\mathrm{HPbI}_{3}(\mathrm{Cl})$ at low $\mathrm{MACl}$ content up to 0.40 is as follows:

$$
\begin{gathered}
\mathrm{HPbI}_{3}+(x+y) \mathrm{MACl} \rightarrow \mathrm{H}_{1-x} \mathrm{~Pb}_{1-x} \mathrm{I}_{3-4 x} \mathrm{Cl}_{x}, \\
+x \mathrm{MAPbI}_{3}+x \mathrm{HI}(\mathrm{g})+y \mathrm{MACl}(\mathrm{g})
\end{gathered}
$$

where the chlorine-incorporated $\mathrm{HPbI}_{3}$, i.e., $\mathrm{H}_{1-x} \mathrm{~Pb}_{1-x} \mathrm{I}_{3-4 x} \mathrm{Cl}_{x}$ is termed as $\mathrm{HPbI}_{3}(\mathrm{Cl})$ hereafter; for $\mathrm{MACl}, x+y$ represents the initial amount of $\mathrm{MACl}$ in the $\mathrm{HPbI}_{3} / \mathrm{MACl}$ precusor solution, $x$ represents the amount of $\mathrm{MACl}$ used for chlorine incorporation, $y$ represents the amount of $\mathrm{MACl}$ that sublimes during thermal annealing.

The as-prepared $\mathrm{HPbI}_{3}(\mathrm{Cl})$ films were then exposed to $\mathrm{CH}_{3} \mathrm{NH}_{2}$ gas atmosphere to form perovskite via the reaction, $\mathrm{CH}_{3} \mathrm{NH}_{2}+\mathrm{H}^{+} \rightarrow \mathrm{CH}_{3} \mathrm{NH}_{3}+20$. As shown in Fig. 1b bottom set, the apparent grain size of the $\mathrm{MAPbI}_{3}(\mathrm{Cl})$ films gradually increases upon the increase of $\mathrm{MACl}$ content. However, too much $\mathrm{MACl}$ is found to cause significant deterioration of the film morphology, especially for the $\mathrm{MACl}$ content of 1.00 case (Supplementary Fig. 9). The structural properties of $\mathrm{MAPbI}_{3}(\mathrm{Cl})$ films were further examined by XRD (Fig. 2a, b and Supplementary Fig. 10). All the samples show a preferred orientation along the (110) crystallographic plane, and the corresponding peak intensity becomes stronger with consecutive substitution of iodine ions by chorine ions. This preferable (110) crystal orientation is induced by the $\mathrm{CH}_{3} \mathrm{NH}_{2}$-based perovskite formation process ${ }^{19,37}$. The gradually increased peak intensity is ascribed to the effect of chlorine on perovskite film growth ${ }^{27,35}$. Furthermore, it was found that the low-angle XRD peak around $14.1^{\circ}$ shifts to a higher two theta value and the peak intensity also increases upon increasing the $\mathrm{MACl}$ content. The same as the aforementioned discussion about the $\mathrm{HPbI}_{3}(\mathrm{Cl})$, substitution of $\mathrm{I}^{-}$ 

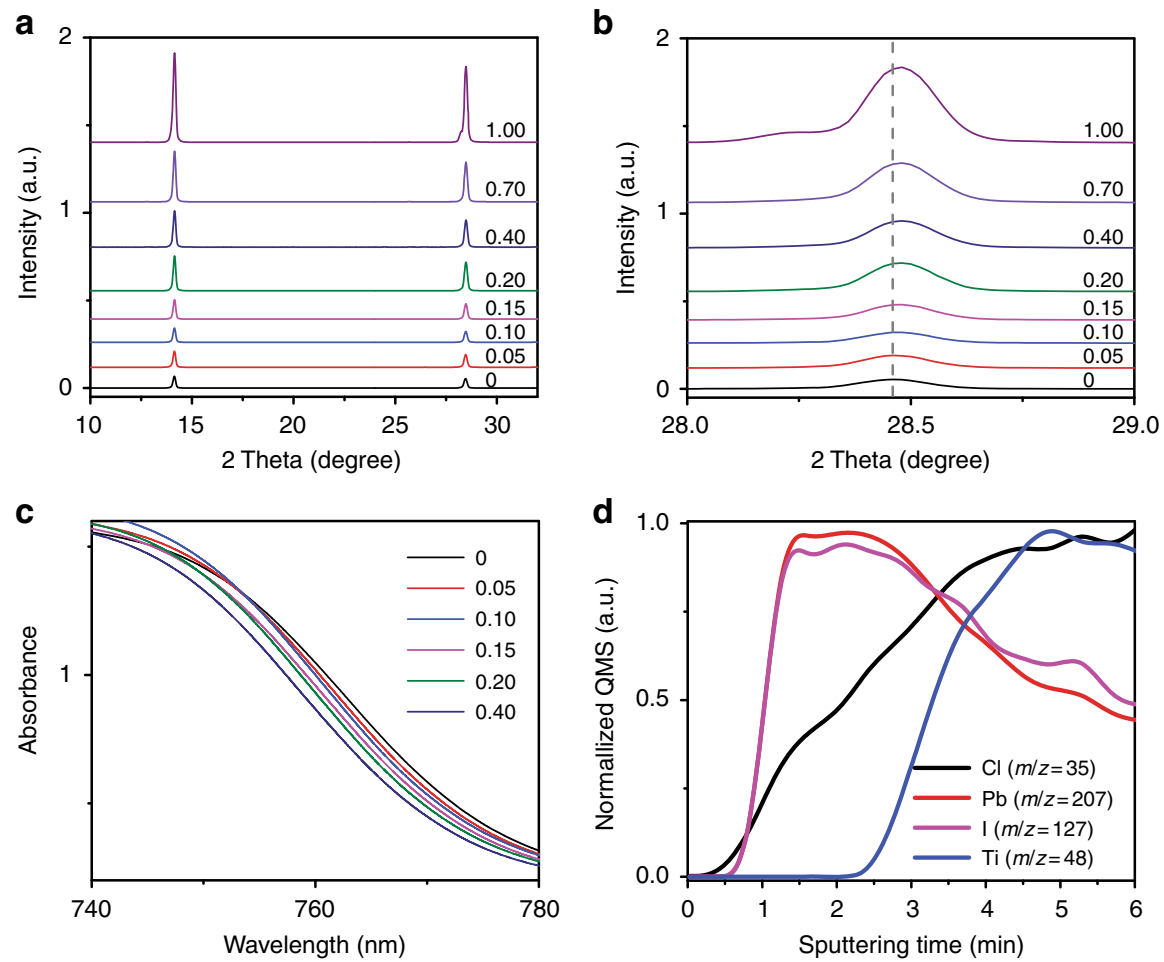

Fig. 2 Partial substitution of iodine ions by chorine ions. $\mathbf{a}, \mathbf{b}$ X-ray diffraction (XRD) patterns of MAPbl $\left.\right|_{3}$ films prepared with different molar ratios of $\mathrm{MACl}$ versus $\mathrm{HPbl}_{3}$ in the $\mathrm{HPbl}_{3} / \mathrm{MACl}$ precursor solution. $\mathbf{c} \mathrm{UV}-\mathrm{Vis}$ spectra of $\mathrm{MAPbl}_{3}$ films prepared with different molar ratios of $\mathrm{MACl}$ versus $\mathrm{HPbl}{ }_{3}$ in the $\mathrm{HPbl}_{3} / \mathrm{MACl}$ precursor solution. d SIMS profiles showing I (magenta), $\mathrm{Pb}$ (red), $\mathrm{Cl}$ (black), and Ti (blue) elements from the top to the bottom of the $\mathrm{MAPbl}_{3}$ film prepared with the molar ratio of $\mathrm{MACl}$ versus $\mathrm{HPbl}_{3}$ to be 0.10 in the $\mathrm{HPbl}_{3} / \mathrm{MACl}$ precursor solution

by smaller-size $\mathrm{Cl}^{-}$can also lead to the shrinkage of the crystal lattice of perovskite, which is consistent with the cell parameters variation (Supplementary Fig. 11). A slight splitting of the XRD peaks is also observed in the case of the MACl content of 1.00, in which the large size mismatch between chloride and iodide precludes the formation of a continuous solid phase of $\mathrm{MAPbI}_{3-x} \mathrm{Cl}_{x}$, and results in phase segregation and large cell parameter variation (Fig. $2 \mathrm{~b}$ and Supplementary Fig. 11). The observed additional peak around $28.2^{\circ}$ is likely associated with the hydrate phase of perovskite ${ }^{38}$.

Although $\mathrm{MACl}$ is introduced into precursor with nominal ratios of $\mathrm{MACl} / \mathrm{HPbI}_{3}$ from 0.1 to 1 , the remaining contents of chlorine in $\mathrm{HPbI}_{3}(\mathrm{Cl})$ and $\mathrm{MAPbI}_{3}(\mathrm{Cl})$ can be significantly lower than the nominal content of chlorine in precursor solution. This is due to the fact that $\mathrm{MACl}$ tends to sublime at elevated temperatures. Furthermore, chlorine tends to form volatile chlorine-containing species, which also tends to gradually diffuse and sublimate from the film, especially in the presence of water $^{25,27}$. Thus, after thermal annealing in open air (relative humidity of about $40-60 \%$ ) the remaining chlorine content in the resultant $\mathrm{MAPbI}_{3}(\mathrm{Cl})$ films is much lower than the chlorine content in the precursor solution. The low content of chlorine in the $\mathrm{MAPbI}_{3}(\mathrm{Cl})$ films is proven by the tiny change in absorption edge (Fig. 2c) ${ }^{39}$. It should be noted that the fluctuation of absorption for the case of $\mathrm{MACl}$ content of 0.70 and 1.00 may be due to the observed slight phase segregation and large roughness (Supplementary Fig. 12) 25,27,35,39. Similar to chorine inclusion, phase segregation is also observed in the bromine inclusion case with high content, i.e., $\left(\mathrm{MAPb}\left(\mathrm{I}_{x} \mathrm{Br}_{1-x}\right)_{3}\right) \quad(0.1<x<0.8)^{40}$, in which perovskite undergo phase separation into iodide-rich and bromide-rich regions under light illumination ${ }^{41}$. In the case of bromine inclusion with low content, the existence of bromine is found to assist grain growth, improve stability, and device performance ${ }^{40-42}$.

To further confirm the existence of chorine in $\mathrm{MAPbI}_{3}(\mathrm{Cl})$ films, we employed secondary-ion mass spectrometry (SIMS) to characterize the depth profile of chlorine in the perovskite film with $\mathrm{MACl}$ content of 0.1 (which gives the best device performance as discussed in the device performance section). As shown in Fig. 2d, the $\mathrm{Cl}$ depth profile exhibits a continuous and gradual increase, and then shows a significant spatial overlap on the Ti profile. This observation is consistent with other reports revealing that the distribution of chlorine within $\mathrm{MAPbI}_{3}(\mathrm{Cl})$ is often inhomogeneous ${ }^{25,43-45}$. One possible cause responsible for the inhomogeneous distribution of chlorine is due to the tendency of chlorine to form volatile chlorine-containing species gradually diffusing and sublimating from the top surface of the film, especially in ambient air, resulting in a gradient increase of the $\mathrm{Cl}$ content from the film surface to bottom ${ }^{25}$. Although the XRD results of the $\mathrm{MAPbI}_{3}(\mathrm{Cl})$ films do not show obvious peaks of $\mathrm{PbCl}_{2}$ or $\mathrm{MAPbCl}_{3}$, it is worth noting that in addition to incorporation into perovskite, the chlorine may form some chloride compounds that are nondetectable by XRD due to the detection limit or the amorphous nature of these compounds. Here, we can complete the second step of $\mathrm{MAPbI}_{3}(\mathrm{Cl})$ formation reaction depicted in Fig. 1a as follows:

$$
\begin{aligned}
& \mathrm{H}_{1-x} \mathrm{~Pb}_{1-x} \mathrm{I}_{3-4 x} \mathrm{Cl}_{x}+x \mathrm{MAPbI}_{3} \\
& +(1-x) \mathrm{CH}_{3} \mathrm{NH}_{2} \rightarrow \mathrm{MAPbI}_{3-x} \mathrm{Cl}_{x},
\end{aligned}
$$

where the chlorine-incorporated perovskite, i.e., $\mathrm{MAPbI}_{3-x} \mathrm{Cl}_{x}$ is termed as $\mathrm{MAPbI}_{3}(\mathrm{Cl})$ hereafter.

Device performance. To study the device performance, we implemented our smooth $1.1-\mu \mathrm{m}$-thick $\mathrm{MAPbI}_{3}(\mathrm{Cl})$ films in the 

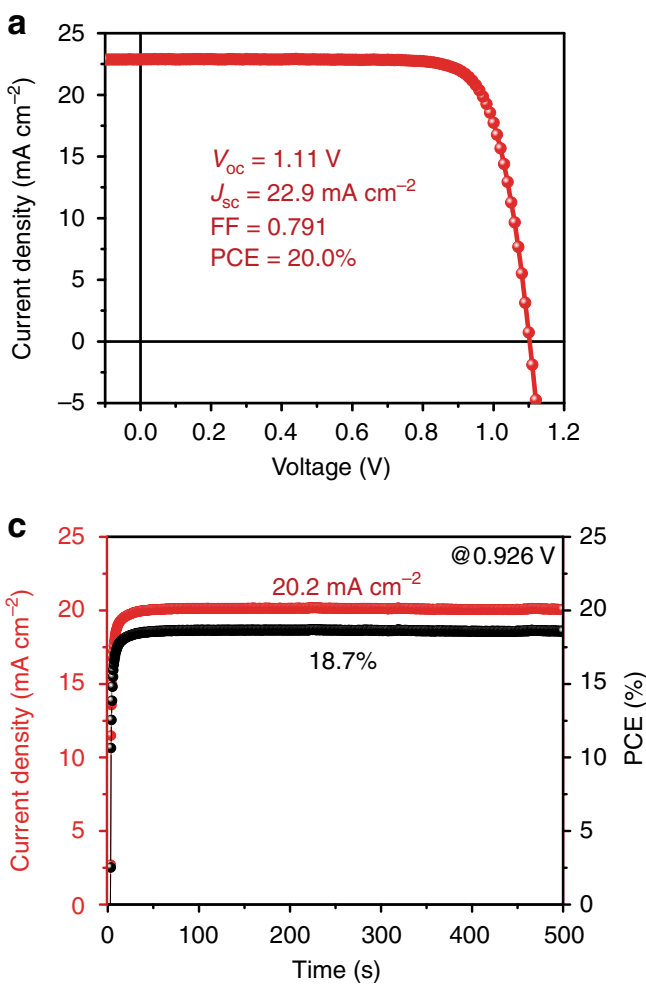
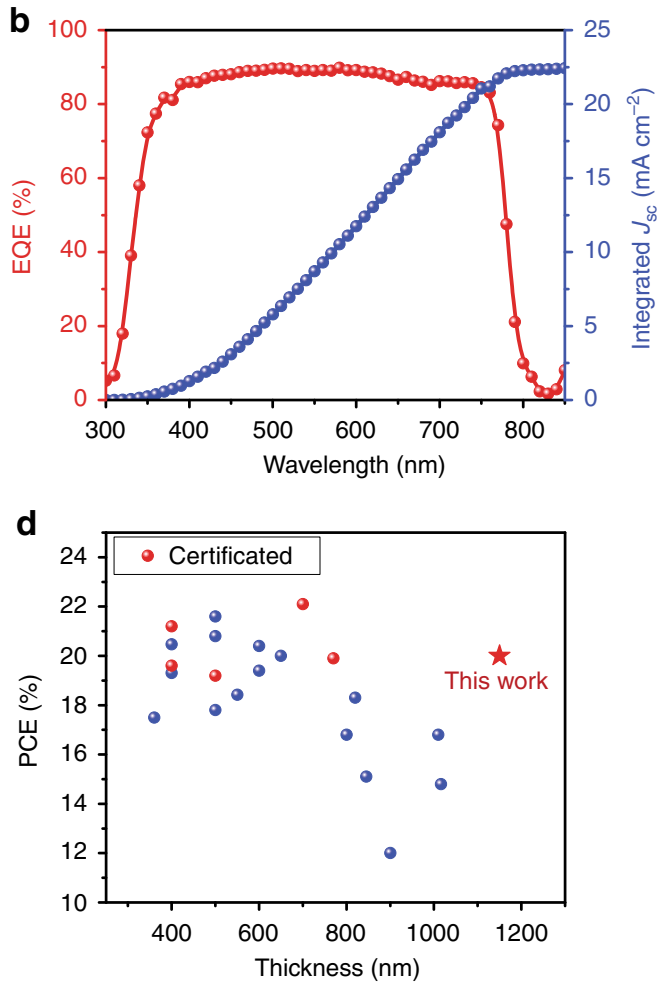

Fig. 3 Photovoltaic performance. a Current density-voltage $(J-V)$ curve for the best performing PSC with AM 1.5 radiation under ambient condition. b External quantum efficiency (EQE) spectrum and integrated $J_{\mathrm{SC}}$ for perovskite solar cells based on the 1.1- $\mu \mathrm{m}$-thick $\mathrm{MAPb} \mathrm{I}_{3}(\mathrm{Cl})$ films. c Stabilized photocurrent density output by holding the voltage at the maximum power point $(0.926 \mathrm{~V})$ for PSCs based on $1.1-\mu \mathrm{m}$-thick $\mathrm{MAPb}{ }_{3}(\mathrm{Cl})$ films. $\mathbf{d}$ Comparison of the PSCs and the corresponding perovskite film thickness in the representative reports and this work (Supplementary Table 1)

device configuration of fluorine-doped tin oxide (FTO) /compact

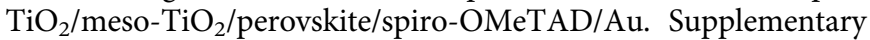
Fig. 13 and Supplementary Table 3 show the device performance results. The $\mathrm{MACl}$ content of 0.10 case delivers the best device performance (Supplementary Note 2) with an average current density $\left(J_{\mathrm{SC}}\right)$ of $22.2 \pm 0.3 \mathrm{~mA} \mathrm{~cm}-2$, open-circuit voltage $\left(V_{\mathrm{OC}}\right)$ of $1.09 \pm 0.02 \mathrm{~V}$, fill factor $(\mathrm{FF})$ of $0.793 \pm 0.015$, and PCE of $19.1 \pm$ $0.4 \%$. As shown in Fig. 3a, a best PCE of $20.0 \%$ was achieved. The integrated $J_{\mathrm{SC}}$ from external quantum efficiency $(\mathrm{EQE})$ is in excellent agreement with current density-voltage $(J-V)$ measurements, with a discrepancy below $2 \%$ (Fig. $3 \mathrm{~b}$ ). The representative $J-V$ curves under different scan directions indicate the negligible hysteresis effect (Supplementary Fig. 14). In addition, a stabilized PCE approaching 19\% for device (with efficiency of $19.2 \%$ from $J-V$ measurements) is also achieved by holding the voltage at the maximum power point for $500 \mathrm{~s}$ (Fig. 3c), which further confirms the negligible hysteresis effect. When compared with reports listed in Supplementary Table 1, the $\operatorname{MAPbI}_{3}(\mathrm{Cl})$ based devices in this work can also deliver a comparable high efficiency with perovskite film thickness over $1.1 \mu \mathrm{m}$ as shown in Fig. 3d. This suggests that at least the 1.1- $\mu$ m-thick $\mathrm{MAPbI}_{3}(\mathrm{Cl})$ layer deposited here does not show a detrimental effect in carrier transport. To further inspect the devices, we performed the crosssectional-view SEM (Fig. 4a). It is found that the grains extend across the entire absorber layer minimizing grain boundaries and providing facile pathways for efficient charge transport. All these results prove that we obtained high-quality thick perovskite films, and high efficiency PSCs can be fabricated based on these films.

Reproducibility is crucial for mass production of low-cost optoelectronic device applications. When compared with PSCs based on perovskite films fabricated using the antisolvent method, our 1.1- $\mu$ m-thick $\mathrm{MAPbI}_{3}(\mathrm{Cl})$ film-based devices show significantly improved reproducibility represented by a much smaller PCE standard deviation (decreasing from $\pm 1.2 \%$ to $\pm 0.4 \%$, Supplementary Fig. 15 and Supplementary Table 4). The high reproducibility of device performance is attributed to the high reproducibility of $1.1-\mu \mathrm{m}$-thick $\mathrm{MAPbI}_{3}(\mathrm{Cl})$ films. To confirm this point, we measured the thickness and roughness of 16 samples of the $1.1-\mu$ m-thick $\mathrm{MAPbI}_{3}(\mathrm{Cl})$ films (Fig. $4 \mathrm{~b}, \mathrm{c}$ and Supplementary Figs. 16, 17). The average thickness and roughness together with their standard deviations are determined to be $1.13 \pm 0.03 \mu \mathrm{m}$ and $5.4 \pm 0.4 \mathrm{~nm}$, respectively. In addition, the device performance of $1.1-\mu \mathrm{m}$-thick $\mathrm{MAPbI}_{3}(\mathrm{Cl})$ devices is higher than that of the devices based on 450-nm-thick perovskite film deposited by the antisolvent method. The higher efficiency for the former case is mainly due to the improved $J_{\mathrm{SC}}$ and FF, which is also supported by the EQE results in Supplementary Fig. 15. This improvement is not only due to the thicker film but also its improved film quality. Moreover, a slightly wider spectral response is observed for the 1.1- $\mu \mathrm{m}$-thick $\mathrm{MAPbI}_{3}(\mathrm{Cl})$ film-based devices. These results suggest that high-quality, thick perovskite films can benefit the enhancement of light harvesting capability, especially at the near-infrared region, towards better device performance.

Development of scalable fabrication processes is key to further industrialization of the PSC technology. We demonstrate that our new perovskite formation method is scalable and can be used to fabricate large-area solar modules. Figure $4 \mathrm{~d}$ shows the optical photograph of $1.1-\mu \mathrm{m}$-thick $\mathrm{MAPbI}_{3}(\mathrm{Cl})$ film on $5 \mathrm{~cm} \times 5 \mathrm{~cm}$ substrates with the mirror-like smooth surface. It is also found that the film is much more uniform over the entire $5 \mathrm{~cm} \times 5 \mathrm{~cm}$ substrate than that of antisolvent case (Supplementary Figs. 18, 
a
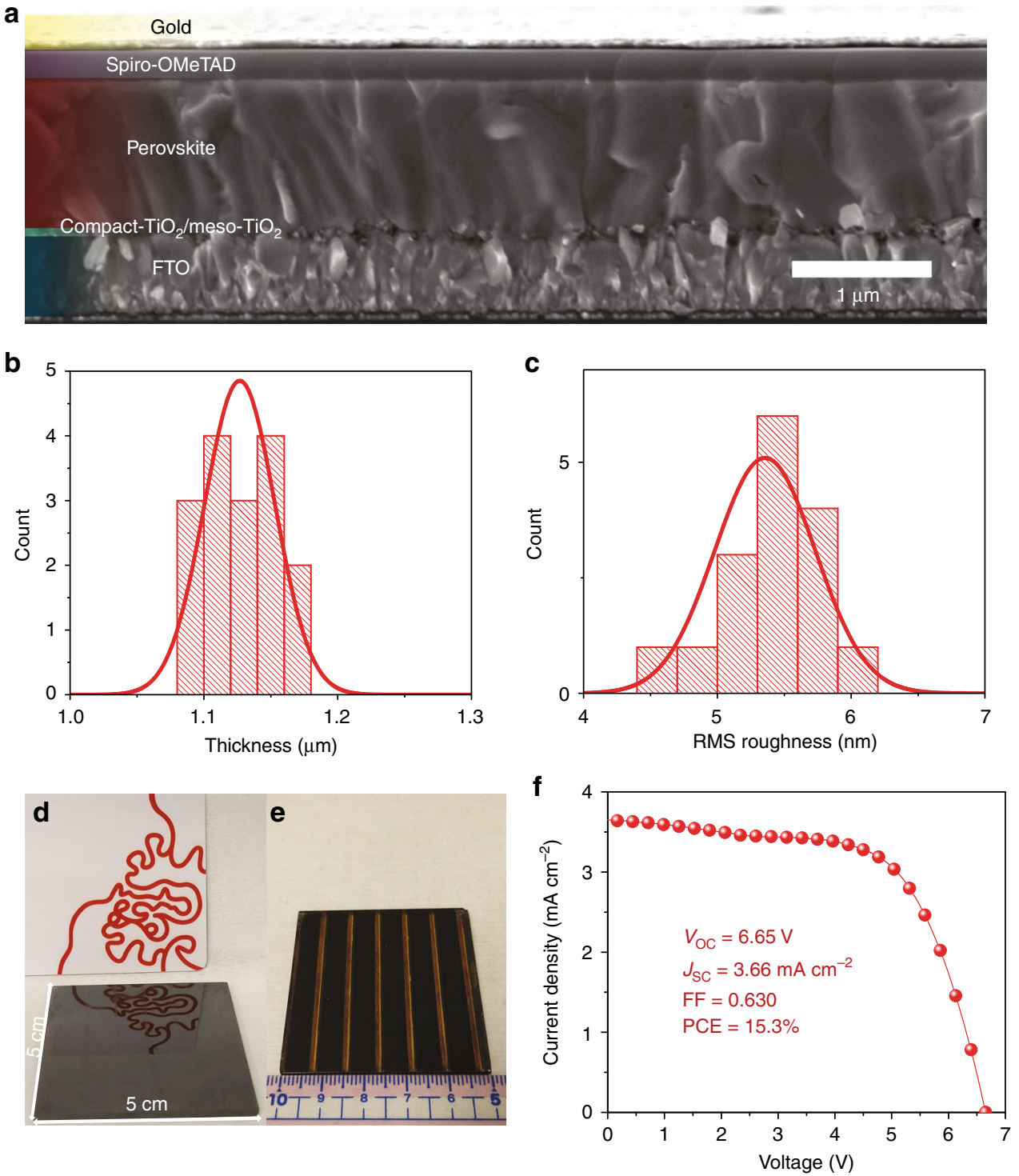

Fig. 4 Solar cells and modules. a Cross-sectional-view SEM image of the PSC based on 1.1- $\mu$ m-thick films. $\mathbf{b}$, $\mathbf{c}$ Histograms of the thickness and root-meansquare (RMS) roughness of $161.1-\mu \mathrm{m}$-thick $\mathrm{MAPbl}_{3}(\mathrm{Cl})$ samples, respectively. $\mathbf{d}$ Photograph of the $1.1-\mu \mathrm{m}$-thick $\mathrm{MAPbl}{ }_{3}(\mathrm{Cl})$ film on a $5 \mathrm{~cm} \times 5 \mathrm{~cm}$ substrate with the mirror-like smooth surface. e Photograph of a $12.0 \mathrm{~cm}^{2}$ six-cell perovskite solar module fabricated using our new method. $\mathbf{f} J-V$ curve of the $5 \mathrm{~cm} \times 5 \mathrm{~cm}$ perovskite module with an active area of $12.0 \mathrm{~cm}^{2}$ based on $1.1-\mu \mathrm{m}$-thick $\mathrm{MAPbl}_{3}(\mathrm{Cl})$ films

19). We then fabricated six-cell modules (active area $=12.0 \mathrm{~cm}^{2}$, geometric fill factor $=48 \%$ ) as shown in Fig. 4e. A best active area PCE of $15.3 \%$ under reverse scan was achieved with a $J_{\text {SC }}$ of 3.66 $\mathrm{mA} \mathrm{cm}{ }^{-2}, V_{\mathrm{OC}}$ of $6.65 \mathrm{~V}$, and FF of 0.630 (Fig. $4 \mathrm{f}$ ), which is among the top PCE values obtained for perovskite solar modules with an active area greater than $10 \mathrm{~cm}^{2} 35,46-56$. Furthermore, our new method shows good reproducibility in the large-area device fabrication with an average module PCE and standard deviation of $13.6 \pm 0.8 \%$ (Supplementary Table 5), which is much better than that of the antisolvent case $(8.6 \pm 1.6 \%$, Supplementary Fig. 20 and Supplementary Table 6). These results further confirm the excellent reproducibility of our $1.1-\mu \mathrm{m}$-thick $\mathrm{MAPbI}_{3}(\mathrm{Cl})$ films on large scale, which is a key advantage for manufacturing in the realistic industrial large-scale setting. Note that small $J-V$ hysteresis was observed for solar modules (Supplementary Fig. 21).

Charge carrier transport behavior. As shown in Fig. 3d, we obtained high efficiencies with $1.1-\mu \mathrm{m}$-thick perovskite films. The promising device performance inspired us to conduct systematical investigations of charge transport properties of our PSC devices to find out what factors lead to the high device performance. We first performed conductive atomic force microscopy (c-AFM) measurements on the 1.1- $\mu$ m-thick $\mathrm{MAPbI}_{3}(\mathrm{Cl})$ film and perovskite film prepared by the antisolvent method (denoted as $\mathrm{MAPbI}_{3}(\mathrm{AS})$ ). It was found that the former shows lower roughness (Supplementary Note 3 ) and rounded large grains with almost four times larger grain size, and its corresponding fewer grain boundaries are expected to reduce the defects density (Supplementary Fig. 22). Moreover, the 1.1- $\mu$ m-thick MAP$\mathrm{bI}_{3}(\mathrm{Cl})$ film also shows nearly an order of magnitude higher lightinduced current (Fig. 5a), which indicates its good electrical conductivity. This observation can be ascribed to the improved crystallinity of the $\mathrm{MAPbI}_{3}(\mathrm{Cl})$ films with preferential (110) orientation (Fig. 5b), as a result of synergistic effect of $\mathrm{CH}_{3} \mathrm{NH}_{2}$ gas ${ }^{19,57}$ and partial substitution of $\mathrm{I}^{-}$by $\mathrm{Cl}^{-11,12}$.

In addition to the improvement in terms of the film morphology and conductivity, the defect nature in perovskite 

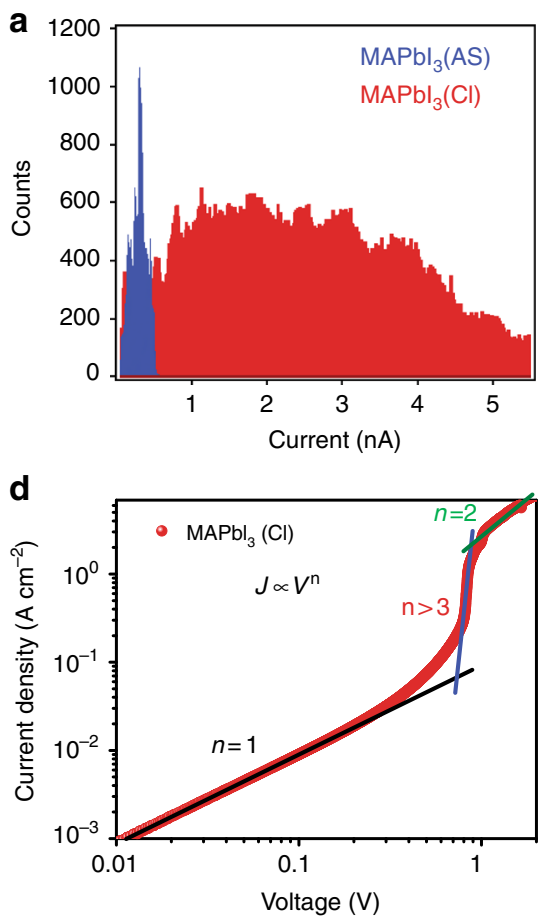

g

$\mathrm{FTO} / \mathrm{MAPbl}_{3}(\mathrm{Cl}) / \mathrm{Au}$

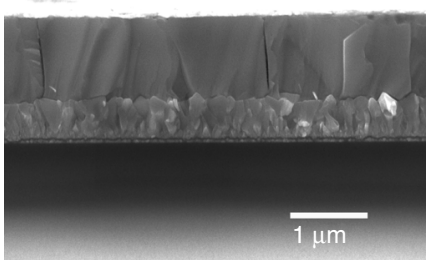

b
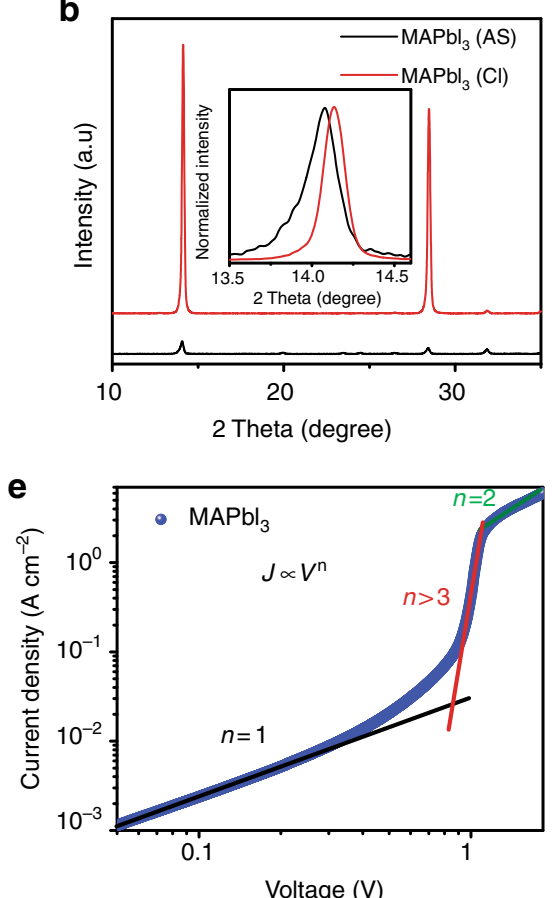

$\mathbf{h}$

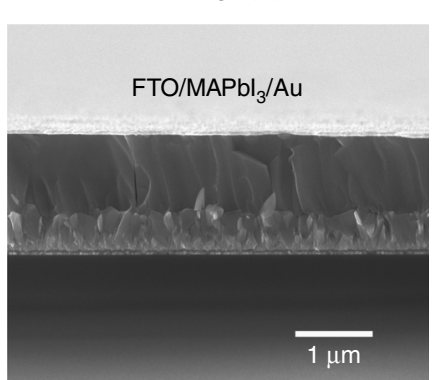

C
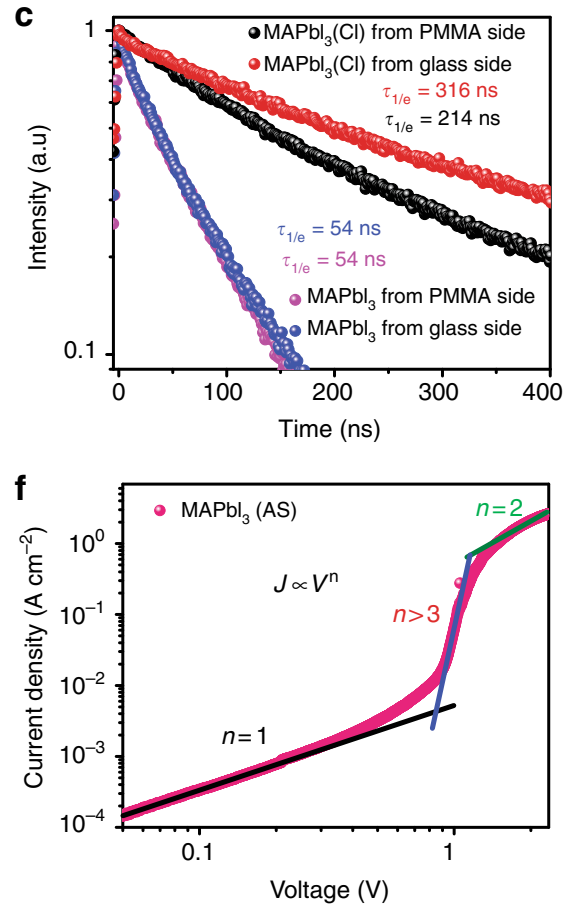

i

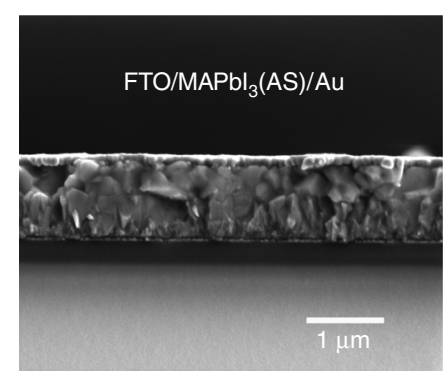

Fig. 5 Charge carrier transport behavior. a The light-induced current extracted from the c-AFM results and $\mathbf{b} X R D$ spectra for $1.1-\mu m$-thick $M A P b l_{3}(C I)$ film prepared by the $\mathrm{HPbl}_{3}(\mathrm{Cl}) / \mathrm{CH}_{3} \mathrm{NH}_{2}$ method and $\mathrm{MAPbl}_{3}(\mathrm{AS})$ film prepared by the antisolvent method. $\mathbf{c}$ Time-resolved photoluminescence (TRPL) decay for 1.1- $\mu$ m-thick $\mathrm{MAPbl}_{3}(\mathrm{Cl})$ and $\mathrm{MAPb}_{3}$ films prepared by the $\mathrm{HPbl}_{3}(\mathrm{Cl}) / \mathrm{CH}_{3} \mathrm{NH}_{2}$ method. $\mathbf{d}$-f Current density-voltage $(J-V)$ characteristics of devices with FTO/perovskite/Au configuration and $\mathbf{g}$-i corresponding cross-sectional-view SEM images utilized for estimating the trap density and mobility for 1.1$\mu$ m-thick $\mathrm{MAPbl}_{3}(\mathrm{Cl})$ and $\mathrm{MAPbl}_{3}$ films prepared by the $\mathrm{HPbl}_{3}(\mathrm{Cl}) / \mathrm{CH}_{3} \mathrm{NH}_{2}$ method, and $\mathrm{MAPbl}(\mathrm{AS})$ film prepared by the antisolvent method. Scale bars: $1 \mu \mathrm{m}$

films may also play a role in influencing charge carrier transport properties $^{58}$. To investigate radiative and nonradiative charge carrier recombination channels within perovskite films, we carried out time-resolved photoluminescence (TRPL) measurements on glass/perovskite/polymethyl methacrylate (PMMA) samples (Supplementary Fig. 23). Figure $5 \mathrm{c}$ shows the TRPL decay curves obtained from both the glass side and PMMA side for the 1.1- $\mu$ m-thick perovskite films with $\left(\mathrm{MAPbI}_{3}(\mathrm{Cl})\right)$ and without (denoted as $\mathrm{MAPbI}_{3}$ ) chlorine incorporation. Considering the limited penetration depth (tens of nanometers) of the light source, the PL emission signal only contains the charge carrier information on the surface layer that is facing the light source ${ }^{59}$. The time constants $(\tau)$ are calculated to be $54 \mathrm{~ns}$ for the $\mathrm{MAPbI}_{3}$ film no matter whether the laser light incidents from the PMMA side or the glass side, which indicates that perovskite on the bottom and top of film has nearly the same charge carrier properties. In the $\mathrm{MAPbI}_{3}(\mathrm{Cl})$ case, the PL lifetime obtained from the glass side is longer than that obtained from the PMMA side. This observation suggests that perovskite on the bottom has better charge carrier properties than the perovskite on the top in $\mathrm{MAPbI}_{3}(\mathrm{Cl})$ film. This observation may be correlated with the inhomogeneous distribution of chlorine within $\mathrm{MAPbI}_{3}(\mathrm{Cl})$ film, where chlorine within a certain range of concentrations can benefit charge carrier properties. Besides, the $\mathrm{MAPbI}_{3}(\mathrm{Cl})$ film shows longer PL lifetimes than that of the $\mathrm{MAPbI}_{3}$ film. This improvement can be ascribed to the better crystallinity and a lower defect density of the $\mathrm{MAPbI}_{3}(\mathrm{Cl})$ film ${ }^{60}$.

To quantitatively evaluate the defect density, we fabricated sandwich devices by inserting the perovskite films between FTO and gold, and characterized the evolution of the space-chargelimited current (SCLC) for different biases, as shown in Fig. 5d-i. In general, the presence of mobile species in perovskite can lead to complication in interpreting the SCLC measurement results, and often precludes a robust quantitative analysis based on such measurements. On the other hand, we observed low hysteresis on the basis of $J-V$ measurements, which indicates a negligible effect of mobile species. Thus, in this case we can safely deduce defects density $\left(N_{\mathrm{t}}\right)$ within perovskite films based on the SCLC measurements according to the equation ${ }^{13,61}$ :

$$
N_{\mathrm{t}}=\frac{2 \varepsilon \varepsilon_{0} V_{\mathrm{TFL}}}{e L^{2}}
$$


where $\varepsilon$ and $\varepsilon_{0}$ are the dielectric constants of perovskite and the vacuum permittivity, respectively, $V_{\mathrm{TFL}}$ is trap-filled limit voltage, $L$ is the thickness of the perovskite films, and $e$ is the elementary charge. We estimated the defect density to be $2.13 \times 10^{15}$ and $2.51 \times 10^{15} \mathrm{~cm}^{-3}$ for the $1.1-\mu \mathrm{m}$-thick $\mathrm{MAPbI}_{3}(\mathrm{Cl})$ film and $\mathrm{MAPbI}_{3}$ film, respectively, prepared by the $\mathrm{HPbI}_{3}(\mathrm{Cl}) / \mathrm{CH}_{3} \mathrm{NH}_{2}$ method (Table 1). These defect density values are significantly lower than antisolvent case $\left(1.48 \times 10^{17} \mathrm{~cm}^{-3}\right)$. The similar magnitude in terms of defects densities derived from the SCLC measurements in contrast with the clear difference in terms of lifetime derived from PL measurements is possibly due to the fact that the former measurement gives the defect information in the entire films, and the latter measurements only provides the defect information for perovskite on the top or bottom of the film. When the bias voltage further increases in the SCLC curves,

\section{Table 1 The SCLC results for FTO/perovskite/Au devices based on 1.1- $\mu \mathrm{m}$-thick $\mathrm{MAPbl}_{3}(\mathrm{Cl})$ and $\mathrm{MAPbl}_{3}$ films prepared by $\mathrm{HPbl}_{3}(\mathrm{Cl}) / \mathrm{CH}_{3} \mathrm{NH}_{2}$ method, and $\mathrm{MAPbl}_{3}(\mathrm{AS})$ film prepared by the antisolvent method}

\begin{tabular}{|c|c|c|c|c|}
\hline Samples & $\begin{array}{l}\text { Thickness } \\
(\mu \mathrm{m})\end{array}$ & $V_{\text {FTL }}(\mathrm{V})$ & $N_{t}\left(\mathrm{~cm}^{-3}\right)$ & $\mu\left(\mathrm{cm}^{2} \mathrm{~V}^{-1} \mathrm{~s}^{-1}\right)$ \\
\hline $\mathrm{MAPbl}_{3}(\mathrm{Cl})$ & 1.1 & 0.73 & $2.13 \times 10^{15}$ & 1.12 \\
\hline $\mathrm{MAPbl}_{3}$ & 1.1 & 0.86 & $2.51 \times 10^{15}$ & 0.83 \\
\hline $\mathrm{MAPbl}_{3}(\mathrm{AS})$ & 0.45 & 0.85 & $1.48 \times 10^{17}$ & 0.014 \\
\hline
\end{tabular}

the current shows a linear relationship with the square of the voltage, where we can deduce the mobility $(\mu)$ from the Mott -Gurney law ${ }^{61}$ :

$$
J_{\mathrm{D}}=\frac{9 \varepsilon \varepsilon_{0} \mu V^{2}}{8 L^{3}}
$$

The mobility are estimated to be 1.12 and $0.83 \mathrm{~cm}^{2} \mathrm{~V}^{-1} \mathrm{~s}^{-1}$ for the 1.1- $\mu \mathrm{m}$-thick $\mathrm{MAPbI}_{3}(\mathrm{Cl})$ film and $\mathrm{MAPbI}_{3}$ film, respectively. The much higher carrier conductivity is consistent with the higher device performance of the $\mathrm{MAPbI}_{3}(\mathrm{Cl})$ case, which again verifies the positive effect of small content chlorine incorporation on the optoelectronic properties of perovskite films. In addition, these mobility values around $1 \mathrm{~cm}^{2} \mathrm{~V}^{-1} \mathrm{~s}^{-1}$ are two orders of magnitude higher than that in antisolvent case $\left(0.014 \mathrm{~cm}^{2} \mathrm{~V}^{-1} \mathrm{~s}^{-1}\right)$, which further confirms the excellent charge carrier transport properties of $\mathrm{CH}_{3} \mathrm{NH}_{2}$ gas-based perovskite films. The improved carrier properties of the $1.1-\mu$ m-thick $\mathrm{MAPbI}_{3}(\mathrm{Cl})$ films when implemented into PSCs is also verified by impedance spectroscopy characterization of devices under light illumination (Table 1 Supplementary Fig. 24 and Supplementary Note 4).

Device stability and perovskite film stability. Operational stability is another key aspect of PSCs. We studied the stability of the small size devices under the operation conditions (Fig. 6a). It was found that the 1.1- $\mu$ m-thick $\mathrm{MAPbI}_{3}(\mathrm{Cl})$-based devices showed much better stability than the $\mathrm{MAPbI}_{3}(\mathrm{AS})$ devices. Especially, the $\mathrm{MAPbI}_{3}(\mathrm{Cl})$ devices maintained over $90 \%$ of their initial performance for $800 \mathrm{~h}$ under continuous light illumination with

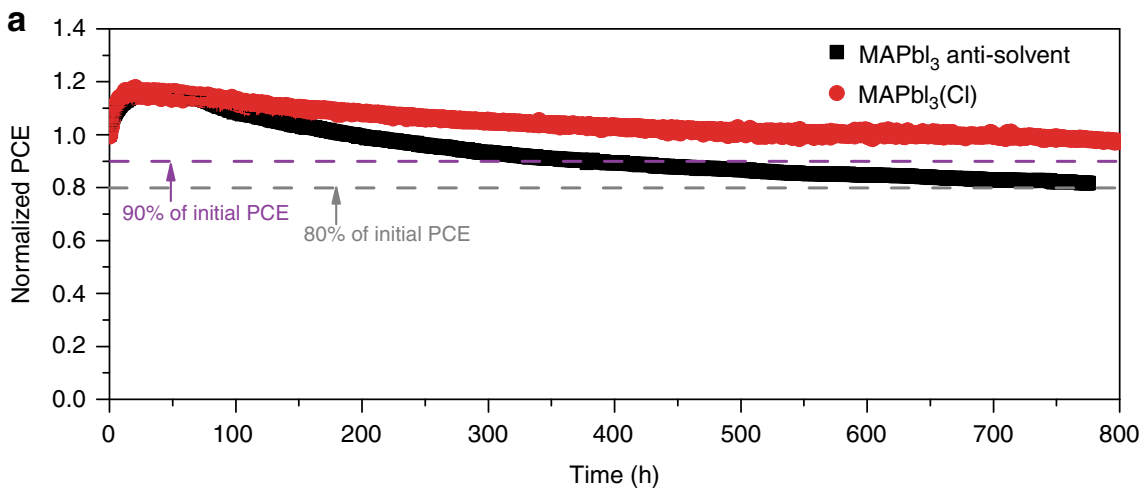

b

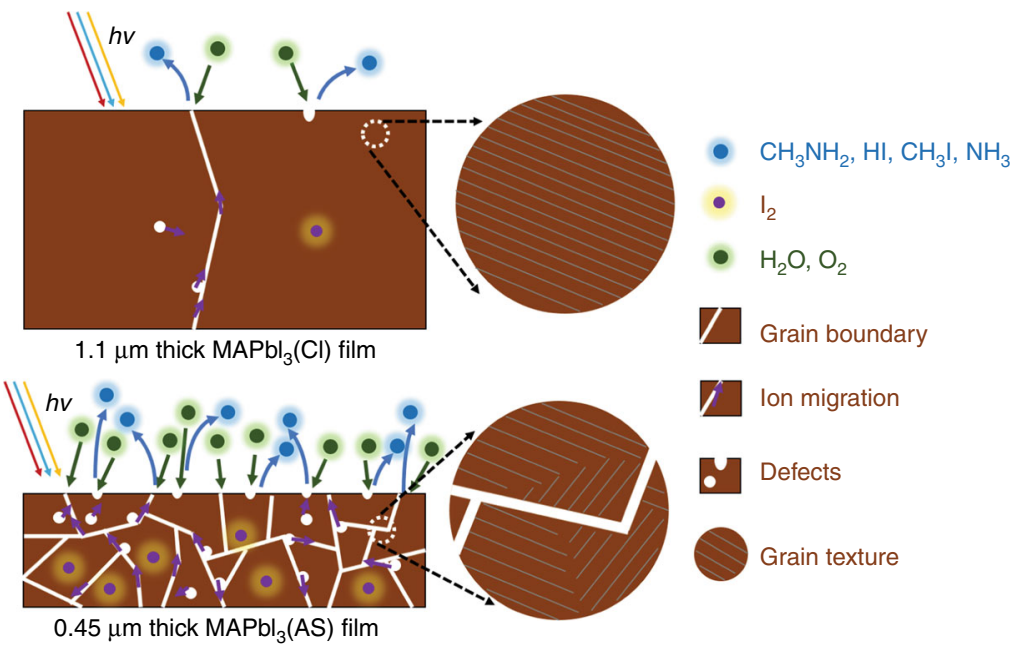

Fig. 6 Device stability and film stability. a Operational stability of un-encapsulated PSCs based on $1.1 \mu \mathrm{m}$ thick $\mathrm{MAPbl}_{3}(\mathrm{Cl})$ films and perovskite films deposited via the antisolvent method examined under continuous full-sun illumination in dry nitrogen atmosphere. b Factors influence film stability of perovskites 
maximum power point tracking (MPPT). While the PCEs of the $\mathrm{MAPbI}_{3}(\mathrm{AS})$ devices decreased to $90 \%$ of their initial performance after approximately $300 \mathrm{~h}$. An initial increase of PCEs for both samples is observed in the first $20 \mathrm{~h}$ of the stability test. A similar phenomenon was also observed previously ${ }^{55,62}$, and was ascribed to the effects such as elevated temperature (approximately $46^{\circ} \mathrm{C}$ ), light or field induced ion movement, light-induced traps formation, interfacial charge accumulation ${ }^{55}$, or spiroOMeTAD conductivity variation ${ }^{63}$. In addition, both devices showed a fast, exponential decay region after reaching the highest performance points, which is followed by a slower linear decay ${ }^{64}$. By fitting the linear region, the $\mathrm{MAPbI}_{3}(\mathrm{Cl})$ devices exhibit a linear slope of $-0.0014 \% \mathrm{~h}^{-1}$, which is $30 \%$ slower than the antisolvent case with a linear slope of $-0.0020 \% \mathrm{~h}^{-1}$. Using these slope values, it is expected to take 1660 and $870 \mathrm{~h}$ of operation to reach the $\mathrm{T}_{80}$ points for $\mathrm{MAPbI}_{3}(\mathrm{Cl})$ devices and the $\mathrm{MAPbI}_{3}(\mathrm{AS})$ devices, respectively. The nearly doubled $\mathrm{T}_{80}$ parameters for the $\mathrm{MAPbI}_{3}(\mathrm{Cl})$ devices suggests the excellent long-term stability of the cells based on our Cl-incorporated thick films. Note that the stability measurements in this study were conducted under operation conditions, i.e., continuous illumination, MPPT, dry $\mathrm{N}_{2}$ gas environment simulating the case of encapsulation, and therefore the results obtained here can be used as a realistic indicator of the device operation lifetime of our PSCs. It should be noted that all of the components in PSCs play an important role in device stability. Considering that $\mathrm{MAPbI}_{3}(\mathrm{Cl})$ devices and $\mathrm{MAPbI}_{3}(\mathrm{AS})$ devices are assembled using the same device configuration, the impact of charge selective layers and electrode on device stability can be excluded out. Hence, the significant stability difference between $\mathrm{MAPbI}_{3}(\mathrm{Cl})$ devices and $\mathrm{MAPbI}_{3}(\mathrm{AS})$ devices is most likely caused by the quality of the perovskite films such as crystallinity, grain size and/or defects, etc. 13,22,34.

To reveal the underlying mechanism responsible for the improved stability, we prepared four kinds of films, i.e., film A: $1.1 \mu \mathrm{m} \mathrm{MAPbI}(\mathrm{Cl})$ film prepared by the $\mathrm{HPbI}_{3}(\mathrm{Cl}) / \mathrm{CH}_{3} \mathrm{NH}_{2}$ method; film B: $1.1 \mu \mathrm{m} \mathrm{MAPbI}_{3}$ film by the $\mathrm{HPbI}_{3} / \mathrm{CH}_{3} \mathrm{NH}_{2}$ method; film C: $0.5 \mu \mathrm{m} \mathrm{MAPbI}_{3}(\mathrm{Cl})$ films prepared by the $\mathrm{HPbI}_{3}(\mathrm{Cl}) / \mathrm{CH}_{3} \mathrm{NH}_{2}$ method; film D: $0.45 \mu \mathrm{m} \mathrm{MAPbI}$ (AS) films prepared by the antisolvent method. We tested the stability of these films under light illumination, a high relative humidity of about $100 \%$ and gentle thermal environment of $50{ }^{\circ} \mathrm{C}$ (denoted as LHT) as shown in Supplementary Fig. 25. It is found that that the stability of these four films is in the order film A $>$ film B $>$ film C $>$ film D (Supplementary Figs. 25 to 28). The improved stability of film A is firstly attributed to its improved grain crystallinity and larger grain size, which can be clearly seen by comparing the XRD peak intensity and full width half maximum of fresh film A with fresh film D (Supplementary Fig. 28b, c and Supplementary Note 5). This is because the ions in highly crystalline perovskite films have higher chemical binding energies to prevent themselves from migrating, which benefits light and thermal stability ${ }^{65}$. This is confirmed by SEM results shown in Supplementary Fig. 29. We found that the decomposition of perovskite mainly started from grain boundaries for all films after $1 \mathrm{~h}$ of LTH testing, where $\mathrm{H}_{2} \mathrm{O}$ and $\mathrm{O}_{2}$ can easily react with perovskite films due to the facts that (1) chemical binding at grain boundaries with low crystallinity is much weaker than that within crystals and (2) the severe ion migration in low crystallinity region especially at grain boundaries facilitates degradation (Fig. 6b) ${ }^{65}$. When further comparing film A with film B, film A shows better crystallinity, larger grain size, and also better stability (Supplementary Figs. 26 to 30). In addition, better stability of films A and B than thinner films C and D also verifies that thicker films are more advantageous in achieving better stability because the extra top layer of the compact high-quality film in the thicker films naturally helps as a protection layer to protect the film underlying the top layer. Besides, previous reports have demonstrated that often a tiny amount of $\mathrm{I}_{2}$ existing in perovskite films can cause severe degradation of perovskite ${ }^{13,66}$. While, $\mathrm{CH}_{3} \mathrm{NH}_{2}$ used here provides an alkaline condition to suppress the formation of $I_{2}$ during the perovskite formation process and/or reduce the $\mathrm{I}_{2}$ amount during the initial degradation of iodine containing perovskite films (Fig. $6 \mathrm{~b}$ and Supplementary Fig. 28f), which may contribute to the better stability of films A, B and C than film $\mathrm{D}^{13,66}$.

\section{Discussion}

A simple perovskite formation method based on fast reaction of chlorine-incorporated $\mathrm{HPbI}_{3}$ and $\mathrm{CH}_{3} \mathrm{NH}_{2}$ has been developed to fabricate high-quality, over $1 \mu \mathrm{m}$ thick and stable $\mathrm{CH}_{3} \mathrm{NH}_{3} \mathrm{PbI}_{3}(\mathrm{Cl})$ perovskite films in ambient condition. The resultant films can not only enable high efficiencies of $19.1 \pm 0.4 \%$ (champion PCE $=20.0 \%$ ) for small size PSCs and $13.6 \pm 0.8 \%$ (champion active area PCE $=15.3 \%$ ) for $5 \mathrm{~cm} \times 5 \mathrm{~cm}$ perovskite solar modules, but also deliver excellent device reproducibility. In addition, the resultant un-encapsulated small size PSCs exhibit an excellent $\mathrm{T}_{80}$ lifetime exceeding $1600 \mathrm{~h}$ under continuous light illumination with MPPT in dry $\mathrm{N}_{2}$ environment. The excellent device stability is mainly a result of the excellent films stability. Our study not only provides a highly reproducible method to fabricate PSCs and modules with enhanced efficiency and stability, but also offers the in-depth understanding for the underlying mechanisms responsible for device stability improvement. The encouraging device performance and excellent stability in this work points out to a promising direction, i.e., use of thick absorber films to realize PSCs and modules with high efficiency, reproducibility, and stability.

\section{Methods}

Materials. All reagents were used as received without further purification, including $\mathrm{PbI}_{2}$ (99.99\%, TCI), hydroiodic acid (57 wt \% in $\mathrm{H}_{2} \mathrm{O}$, distilled, stabilized, $99.95 \%$, Sigma-Aldrich), chlorobenzene ( $99.8 \%$, Wako), methylamine (40\% in methanol, TCI), 2,2',7,7'-tetrakis( $N, N$-di-p-methoxyphenylamine)-9,9'-spirobifluorene (spiroOMeTAD, Merck), N,N-dimethylformamide (DMF, 99.99\%, Sigma-Aldrich), methylammonium chloride (Wako), ethanol (Wako), HI (57\%, Alfa Aesar), 4-tertbutylpyridine (99.9\%, Sigma-Aldrich), acetonitrile (99.9\%, Sigma-Aldrich), titanium diisopropoxide bis(acetylacetonate) (75 wt $\%$ in isopropanol, Sigma-Aldrich), $n$-butyl alcohol (Sigma-Aldrich), FTO glasses (7-8 $\Omega \mathrm{sq}^{-1}$, Opvtech.), $\mathrm{TiO}_{2}$ (DyeSol, 30 NR-D).

Synthesis of $\mathrm{HPbI}_{3}$ : The $\mathrm{HPbI}_{3}$ crystals were prepared using an antisolvent vapor-assisted crystallization method as shown in Supplementary Fig. 2. Briefly, $11 \mathrm{~g} \mathrm{PbI}_{2}$ and $7 \mathrm{~g}$ of $\mathrm{HI}$ were mixed and dissolved in $17 \mathrm{~g}$ of DMF to form an $\mathrm{HPbI}_{3}$ solution. The $\mathrm{HPbI}_{3}$ solution was heated at $100{ }^{\circ} \mathrm{C}$ in chlorobenzene vapor environment for $24 \mathrm{~h}$. During this heat-treatment, chlorobenzene diffuses into the $\mathrm{HPbI}_{3} / \mathrm{DMF}$ solution and reduces the solubility of $\mathrm{HPbI}_{3}$. Light yellow needle-like $\mathrm{HPbI}_{3}$ crystals were formed, which were collected and washed with chlorobenzene/ DMF (volume ratio $=3: 1$ ) for three times and then washed with ethanol for three times. Finally, the $\mathrm{HPbI}_{3}$ crystals were dried at $60{ }^{\circ} \mathrm{C}$ for $24 \mathrm{~h}$ under vacuum.

Fabrication of perovskite films and solar cells. To study the dependence of the film thickness on preparation conditions, the $\mathrm{HPbI}_{3}$ films are obtained by spincoating $\mathrm{HPbI}_{3}$ precursor $\left(60 \mathrm{wt} \% \mathrm{HPbI}_{3}\right.$ in $\left.\mathrm{DMF}\right)$ at $5000 \mathrm{rpm}$ for $30 \mathrm{~s}$ on substrates under different temperatures (room temperature, $60,70,80,90,100^{\circ} \mathrm{C}$ ) in ambient air condition. For chlorine-incorporated perovskite deposition, the precursor solutions containing different molar ratios of $\mathrm{MACl} / \mathrm{HPbI}_{3}(0,0.05,0.10$, $0.15,0.20,0.40,0.70,1.00)$ are deposited on substrates preheated at $90{ }^{\circ} \mathrm{C}$ at 5000 rpm for $30 \mathrm{~s}$. After thermal annealing at $100^{\circ} \mathrm{C}$ for $5 \mathrm{~min}$ to remove the solvent, part of the $\mathrm{MACl}$ and also part or all of the formed $\mathrm{HI}$ during this process, the obtained films react with $\mathrm{CH}_{3} \mathrm{NH}_{2}$ gas to form perovskite ${ }^{20,22}$. Then the obtained perovskite films are annealed at $100{ }^{\circ} \mathrm{C}$ for $5 \mathrm{~min}$ in ambient air condition before device fabrication or other characterization. A $30 \mu \mathrm{L}$ of spiro-OMeTAD was spin coated on the perovskite film at $3000 \mathrm{rpm}$ for $30 \mathrm{~s}$, where a spiro-OMeTAD/ chlorobenzene $\left(72.3 \mathrm{mg} \mathrm{mL}^{-1}\right)$ solution was employed with the addition of $17.5 \mu \mathrm{L}$ Li-TFSI/acetonitrile $\left(520 \mathrm{mg} \mathrm{mL}^{-1}\right)$, and $28.8 \mu \mathrm{L}$ 4-tert-butylpyridine. Finally, a gold layer with a thickness of $100 \mathrm{~nm}$ was deposited as the counter electrode on the top of spiro-OMeTAD layer through shadow masks via thermal evaporation under high vacuum $\left(5 \times 10^{-5}\right.$ Torr $)$. 
Characterization. Current-voltage $(J-V)$ characteristics of PSCs are measured under one sun illumination (AM $1.5 \mathrm{G}, 100 \mathrm{~mW} \mathrm{~cm}^{-2}$, calibrated using a Newport reference Si-cell, Oriel Instruments Model Number 90026564, $2 \times 2 \mathrm{~cm}^{2}$ ) using a solar simulator (Newport Oriel Sol 1A, Xenon-lamp, USHIO, UXL-150SO) and a Keithley 2400 source meter in ambient air at about $25^{\circ} \mathrm{C}$ and a relative humidity of about $40-60 \%$. The small size PSCs were measured using a $0.1 \mathrm{~cm}^{2}$ metal mask. No mask is used for measurement of perovskite modules. The active area of perovskite modules is $12.0 \mathrm{~cm}^{2}$, determined by the overlap areas of top and bottom electrodes described in our previous publication ${ }^{46}$. All the $J-V$ curves are measured under reverse scan with a scan rate of $0.25 \mathrm{~V} \mathrm{~s}^{-1}$ without preconditioning unless otherwise specified. For stability measurements, the cells were subsequently loaded in our home-designed environmental chamber coupled with a solar simulator (Peccell PEC-L01, AM1.5G) and source meter (Keithley 2401) controlled by a LabView program allowing automatic sequential measurements on the devices with adjustable acquisition time intervals. To simulate continuous solar cell operation an active bias voltage was applied to the cells maintaining the solar cell operation at the maximum power point. The devices were kept at the maximum power output voltage during the intervals between consecutive measurements. No UV-filters were used, i.e., the UV component is included in illumination. The stability measurement was performed under nitrogen box with a relative humidity below 5\%. EQE measurements were performed on an Oriel IQE 200 in DC mode.

SEM measurements was carried out in scanning electron microscope (Helios NanoLab G3 UC, FEI). XRD measurements were carried out in a Bruker D8 Discover instrument (Bruker AXS GmbH, Karlsruhe, Germany) equipped with $\mathrm{Cu}$ wavelength $\lambda=1.54 \AA$ X-ray source operated at $1600 \mathrm{~W}$ and Goebel mirror. Data were collected from 5 to 60 two theta degrees with a 0.02 degrees step. Experimental data were fitted to obtain unit cell phase parameters using the Profex/ BGMN software (v.3.12.0, http://profex.doebelin.org/). TRPL was acquired using the time-correlated, single-photon counting technique (Hamamatsu, C10627), and excitation was provided by a femtosecond mode-locked Ti:sapphire laser (SpectraPhysics, MAITAI XF-IMW) at $450 \mathrm{~nm}$ with an average power at $8 \mathrm{MHz}$ of 0.74 $\mathrm{mW}$. In TRPL, perovskite films were covered with PMMA on the top of the perovskite layer to exclude/minimize the influence of ambient air (especially the influence from $\mathrm{H}_{2} \mathrm{O}$ and $\left.\mathrm{O}_{2}\right)^{67-70}$. SIMS (Kratos Axis ULTRA) equipped with quadrupole mass spectrometer (HAL 7, Hiden Analytical) was used to collect the elemental signal in positive ion detection mode (PID). For sputtering in SIMS, 3 $\mathrm{keV} \mathrm{Ar}^{+}$primary beam with a $10 \mathrm{~mA}$ current and diameter of $100 \mu \mathrm{m}$ were utilized. The beam was set at an angle of $45^{\circ}$ with respect to the sample surface normal. The spectrometer was operated at a pressure of $10^{-8}$ Torr. The c-AFM measurement of the films was performed in contact-mode (MFP-3D series, Asylum Research) in ambient conditions $\left(35 \% \mathrm{RH}, 22^{\circ} \mathrm{C}\right)$. Top side illumination was generated with a halogen lamp. Chromium/platinum-coated cantilevers with a nominal spring constant of $0.2 \mathrm{~N} \mathrm{~m}^{-1}$ were used to collect the photo-generated currents. The SCLC data were collected with a semiconductor characterization system in $\mathrm{N}_{2}$ (4200-SCS, Keithley). Absorbance was measured using a UV-Vis spectrometer (JASCO Inc., V-670). Impedance Spectroscopy measurements had been recorded with an Autolab PGSTAT204 potentiostat equipped with a frequency response analyzer module FRA32, AC perturbation was set to $10 \mathrm{mV}$ and frequency ranged between $1 \mathrm{MHz}$ to $0.5 \mathrm{~Hz}$. The measurements were done in $\mathrm{N}_{2}$ environment with less than $0.1 \%$ relative humidity, and Oriel VeraSol-2class AAALED light source simulating AM 1.5 spectra.

\section{Data availability}

The data that support the findings of this study are available from the corresponding author on reasonable request.

Received: 29 April 2018 Accepted: 24 August 2018

Published online: 24 September 2018

\section{References}

1. Kojima, A., Teshima, K., Shirai, Y. \& Miyasaka, T. Organometal halide perovskites as visible-light sensitizers for photovoltaic cells. J. Am. Chem. Soc. 131, 6050-6051 (2009).

2. Kim, H.-S. et al. Lead iodide perovskite sensitized all-solid-state submicron thin film mesoscopic solar cell with efficiency exceeding 9\%. Sci. Rep. 2, 591 (2012).

3. Lee, M. M., Teuscher, J., Miyasaka, T., Murakami, T. N. \& Snaith, H. J. Efficient hybrid solar cells based on meso-superstructured organometal halide perovskites. Science 338, 643-647 (2012).

4. Green, M. A., Ho-Baillie, A. \& Snaith, H. J. The emergence of perovskite solar cells. Nat. Photon. 8, 506-514 (2014).

5. Gratzel, M. The light and shade of perovskite solar cells. Nat. Mater. 13, 838-842 (2014).

6. Yang, W. S. et al. Iodide management in formamidinium-lead-halide-based perovskite layers for efficient solar cells. Science 356, 1376-1379 (2017).
7. Jeon, N. J. et al. Solvent engineering for high-performance inorganic-organic hybrid perovskite solar cells. Nat. Mater. 13, 897-903 (2014).

8. Xiao, M. et al. A fast deposition-crystallization procedure for highly efficient lead iodide perovskite thin-film solar cells. Angew. Chem. 126, 10056-10061 (2014).

9. Ahn, N. et al. Highly reproducible perovskite solar cells with average efficiency of $18.3 \%$ and best efficiency of $19.7 \%$ fabricated via lewis base adduct of lead (II) iodide. J. Am. Chem. Soc. 137, 8696-8699 (2015).

10. Burschka, J. et al. Sequential deposition as a route to high-performance perovskite-sensitized solar cells. Nature 499, 316-319 (2013).

11. Stranks, S. D. et al. Electron-hole diffusion lengths exceeding 1 micrometer in an organometal trihalide perovskite absorber. Science 342, 341-344 (2013).

12. Xing, G. et al. Long-range balanced electron- and hole-transport lengths in organic-inorganic $\mathrm{CH}_{3} \mathrm{NH}_{3} \mathrm{PbI}_{3}$. Science 342, 344-347 (2013).

13. Liu, Z. et al. Chemical reduction of intrinsic defects in thicker heterojunction planar perovskite solar cells. Adv. Mater. 29, 1606774 (2017).

14. Yuan, Z. et al. Approximately $800-\mathrm{nm}$-thick pinhole-free perovskite films via facile solvent retarding process for efficient planar solar cells. ACS Appl. Mater. Interfaces 8, 34446-34454 (2016).

15. Chen, Z. et al. Thin single crystal perovskite solar cells to harvest belowbandgap light absorption. Nat. Commun. 8, 1890 (2017).

16. Li, C., Pang, S., Xu, H. \& Cui, G. Methylamine gas based synthesis and healing process toward upscaling of perovskite solar cells: progress and perspective. Sol. RRL 1, 1700076 (2017).

17. Zhou, Y. \& Padture, N. P. Gas-induced formation/transformation of organic-inorganic halide perovskites. ACS Energy Lett. 2, 2166-2176 (2017).

18. Raga, S. R., Jiang, Y., Ono, L. K. \& Qi, Y. B. Application of methylamine gas in fabricating organic-inorganic hybrid perovskite solar cells. Energy Tech. $\mathbf{5}$, 1750-1761 (2017).

19. Zhou, Z. et al. Methylamine-gas-induced defect-healing behavior of $\mathrm{CH}_{3} \mathrm{NH}_{3} \mathrm{PbI}_{3}$ thin films for perovskite solar cells. Angew. Chem. Int. Ed. $\mathbf{5 4}$ 9705-9709 (2015).

20. Pang, S. et al. Transformative evolution of organolead triiodide perovskite thin films from strong room-temperature solid-gas interaction between $\mathrm{HPbI}_{3}$ $\mathrm{CH}_{3} \mathrm{NH}_{2}$ precursor pair. J. Am. Chem. Soc. 138, 750-753 (2016).

21. Zhang, Y. et al. Trash into treasure: $\delta-\mathrm{FAPbI}_{3}$ polymorph stabilized $\mathrm{MAPb}_{3}$ perovskite with power conversion efficiency beyond $21 \%$. Adv. Mater. 30, 1707143 (2018)

22. Long, $\mathrm{M}$. et al. Textured $\mathrm{CH}_{3} \mathrm{NH}_{3} \mathrm{PbI}_{3}$ thin film with enhanced stability for high performance perovskite solar cells. Nano Energy 33, 485-496 (2017).

23. Noel, N. K. et al. A low viscosity, low boiling point, clean solvent system for the rapid crystallisation of highly specular perovskite films. Energy Environ. Sci. 10, 145-152 (2017).

24. Nenon, D. P. et al. Structural and chemical evolution of methylammonium lead halide perovskites during thermal processing from solution. Energy Environ. Sci. 9, 2072-2082 (2016).

25. Aguiar, J. A. et al. In situ investigation of halide incorporation into perovskite solar cells. MRS Commun. 7, 575-582 (2017).

26. Xie, F. X., Su, H., Mao, J., Wong, K. S. \& Choy, W. C. H. Evolution of diffusion length and trap state induced by chloride in perovskite solar cell. J. Phys. Chem. C 120, 21248-21253 (2016).

27. Zhao, Y. \& Zhu, K. $\mathrm{CH}_{3} \mathrm{NH}_{3} \mathrm{Cl}$-assisted one-step solution growth of $\mathrm{CH}_{3} \mathrm{NH}_{3} \mathrm{PbI}_{3}$ : structure, charge-carrier dynamics, and photovoltaic properties of perovskite solar cells. J. Phys. Chem. C 118, 9412-9418 (2014).

28. Williams, S. T. et al. Role of chloride in the morphological evolution of organo-lead halide perovskite thin films. ACS Nano 8, 10640-10654 (2014).

29. Zhou, H. et al. Interface engineering of highly efficient perovskite solar cells. Science 345, 542-546 (2014)

30. Chen, Q. et al. The optoelectronic role of chlorine in $\mathrm{CH}_{3} \mathrm{NH}_{3} \mathrm{PbI}_{3}(\mathrm{Cl})$-based perovskite solar cells. Nat. Commun. 6, 7269 (2015).

31. Colella, S. et al. $\mathrm{MAPbI}_{3-\mathrm{x}} \mathrm{Cl}_{\mathrm{x}}$ mixed halide perovskite for hybrid solar cells: the role of chloride as dopant on the transport and structural properties. Chem. Mater. 25, 4613-4618 (2013).

32. Deng, Y. et al. Scalable fabrication of efficient organolead trihalide perovskite solar cells with doctor-bladed active layers. Energy Environ. Sci. 8, 1544-1550 (2015).

33. Wang, F., Yu, H., Xu, H. \& Zhao, N. $\mathrm{HPbI}_{3}$ : a new precursor compound for highly efficient solution-processed perovskite solar cells. Adv. Funct. Mater. 25, 1120-1126 (2015).

34. Long, $\mathrm{M}$. et al. Nonstoichiometric acid-base reaction as reliable synthetic route to highly stable $\mathrm{CH}_{3} \mathrm{NH}_{3} \mathrm{PbI}_{3}$ perovskite film. Nat. Commun. 7, 13503 (2016).

35. Yang, M. et al. Perovskite ink with wide processing window for scalable highefficiency solar cells. Nat. Energy 2, 17038 (2017).

36. Zhao, L. et al. Redox chemistry dominates the degradation and decomposition of metal halide perovskite optoelectronic devices. ACS Energy Lett. 1, 595-602 (2016). 
37. Chang, Y. et al. $\mathrm{CH}_{3} \mathrm{NH}_{2}$ gas induced (110) preferred cesium-containing perovskite film with reduced $\mathrm{PbI}_{6}$ octahedron distortion and enhanced moisture stability. J. Mater. Chem. A 5, 4803-4808 (2017).

38. Shirayama, M. et al. Degradation mechanism of $\mathrm{CH}_{3} \mathrm{NH}_{3} \mathrm{PbI}_{3}$ perovskite materials upon exposure to humid air. J. Appl. Phys. 119, 115501 (2016).

39. Li, Y. et al. H High-performance planar solar cells based on $\mathrm{CH}_{3} \mathrm{NH}_{3} \mathrm{PbI}_{3-\mathrm{x}} \mathrm{Cl}_{\mathrm{x}}$ perovskites with determined chlorine mole fraction. Adv. Funct. Mater. 25, 4867-4873 (2015).

40. Hoke, E. T. et al. Reversible photo-induced trap formation in mixed-halide hybrid perovskites for photovoltaics. Chem. Sci. 6, 613-617 (2015).

41. Slotcavage, D. J., Karunadasa, H. I. \& McGehee, M. D. Light-induced phase segregation in halide-perovskite absorbers. ACS Energy Lett. 1, 1199-1205 (2016).

42. Yang, M. et al. Facile fabrication of large-grain $\mathrm{CH}_{3} \mathrm{NH}_{3} \mathrm{PbI}_{3-\mathrm{x}} \mathrm{Br}_{\mathrm{x}}$ films for high-efficiency solar cells via $\mathrm{CH}_{3} \mathrm{NH}_{3} \mathrm{Br}$-selective Ostwald ripening. Nat. Commun. 7, 12305 (2016).

43. Starr, D. E. et al. Direct observation of an inhomogeneous chlorine distribution in $\mathrm{CH}_{3} \mathrm{NH}_{3} \mathrm{PbI}_{3-\mathrm{x}} \mathrm{Cl}_{\mathrm{x}}$ layers: surface depletion and interface enrichment. Energy Environ. Sci. 8, 1609-1615 (2015).

44. Cao, C. et al. Iodine and chlorine element evolution in $\mathrm{CH}_{3} \mathrm{NH}_{3} \mathrm{PbI}_{3-\mathrm{x}} \mathrm{Cl}_{\mathrm{x}}$ thin films for highly efficient planar heterojunction perovskite solar cells. Chem. Mater. 28, 2742-2749 (2016).

45. Luo, Y. et al. Spatially heterogeneous chlorine incorporation in organic-inorganic perovskite solar cells. Chem. Mater. 28, 6536-6654 (2016).

46. Jiang, Y. et al. Combination of hybrid CVD and cation exchange for upscaling Cs-substituted mixed cation perovskite solar cells with high efficiency and stability. Adv. Funct. Mater. 28, 1703835 (2017).

47. $\mathrm{Bu}, \mathrm{T}$. et al. A novel quadruple-cation absorber for universal hysteresis elimination for high efficiency and stable perovskite solar cells. Energy Environ. Sci. 10, 2509-2515 (2017)

48. Chen, H. et al. A solvent- and vacuum-free route to large-area perovskite films for efficient solar modules. Nature 550, 92-95 (2017).

49. Chiang, C.-H., Nazeeruddin, M. K., Gratzel, M. \& Wu, C.-G. The synergistic effect of $\mathrm{H}_{2} \mathrm{O}$ and DMF towards stable and $20 \%$ efficiency inverted perovskite solar cells. Energy Environ. Sci. 10, 808-817 (2017).

50. Qiu, W. et al. Pinhole-free perovskite films for efficient solar modules. Energy Environ. Sci. 9, 484-489 (2016)

51. Leyden, M. R., Jiang, Y. \& Qi, Y. B. Chemical vapor deposition grown formamidinium perovskite solar modules with high steady state power and thermal stability. J. Mater. Chem. A 4, 13125-13132 (2016).

52. Liao, H. C. et al. Enhanced efficiency of hot-cast large-area planar perovskite solar cells/modules having controlled chloride incorporation. Adv. Energy Mater. 7, 1601660 (2017).

53. Yeo, J.-S. et al. Reduced graphene oxide-assisted crystallization of perovskite via solution-process for efficient and stable planar solar cells with modulescales. Nano Energy 30, 667-676 (2016).

54. Heo, J. H., Han, H. J., Kim, D., Ahn, T. K. \& Im, S. H. Hysteresis-less inverted $\mathrm{CH}_{3} \mathrm{NH}_{3} \mathrm{PbI}_{3}$ planar perovskite hybrid solar cells with $18.1 \%$ power conversion efficiency. Energy Environ. Sci. 8, 1602-1608 (2015).

55. Grancini, G. et al. One-year stable perovskite solar cells by $2 \mathrm{D} / 3 \mathrm{D}$ interface engineering. Nat. Commun. 8, 15684 (2017).

56. Li, Z. et al. Scalable fabrication of perovskite solar cells. Nat. Rev. Mater. 3 18017 (2018)

57. Zhang, M.-J. et al. Carrier transport improvement of $\mathrm{CH}_{3} \mathrm{NH}_{3} \mathrm{PbI}_{3}$ film by methylamine gas treatment. Acs Appl. Mater. Interfaces 8, 31413-31418 (2016).

58. Ball, J. M. \& Petrozza, A. Defects in perovskite-halides and their effects in solar cells. Nat. Energy 1, 16149 (2016).

59. Ding, J., Lian, Z., Li, Y., Wang, S. \& Yan, Q. The role of surface defects in photoluminescence and decay dynamics of high-quality perovskite MAPbI3 single crystals. J. Phys. Chem. Lett. 9, 4221-4226 (2018).

60. $\mathrm{Wu}, \mathrm{X}$. et al. Trap states in lead iodide perovskites. J. Am. Chem. Soc. 137, 2089-2096 (2015).

61. Dong, Q. et al. Electron-hole diffusion lengths $>175 \mu \mathrm{m}$ in solution-grown $\mathrm{CH}_{3} \mathrm{NH}_{3} \mathrm{PbI}_{3}$ single crystals. Science 347, 967-970 (2015).

62. Hou, Y. et al. A generic interface to reduce the efficiency-stability-cost gap of perovskite solar cells. Science 358, 1192-1197 (2017).

63. Hawash, Z., Ono, L. K. \& Qi, Y. B. Moisture and oxygen enhance conductivity of LiTFSI-doped spiro-MeOTAD hole transport layer in perovskite solar cells. Adv. Mater. Interfaces 3, 1600117 (2016).
64. Domanski, K., Alharbi, E. A., Hagfeldt, A., Grätzel, M. \& Tress, W. Systematic investigation of the impact of operation conditions on the degradation behaviour of perovskite solar cells. Nat. Energy 3, 61-67 (2018).

65. Yuan, Y. \& Huang, J. Ion migration in organometal trihalide perovskite and its impact on photovoltaic efficiency and stability. Acc. Chem. Res. 49, 286-293 (2016).

66. Wang, S., Jiang, Y., Juarez-Perez, EmilioJ., Ono, LuisK. \& Qi, Y. B. Accelerated degradation of methylammonium lead iodide perovskites induced by exposure to iodine vapour. Nat. Energy 2, 16195 (2016)

67. Galisteo-López, J. F., Anaya, M., Calvo, M. E. \& Míguez, H. Environmental effects on the photophysics of organic-inorganic halide perovskites. J. Phys. Chem. Lett. 6, 2200-2205 (2015).

68. Fang, H.-H. et al. Ultrahigh sensitivity of methylammonium lead tribromide perovskite single crystals to environmental gases. Sci. Adv. 2, e1600534 (2016).

69. Brenes, R. et al. Metal halide perovskite polycrystalline films exhibiting properties of single crystals. Joule 1, 155-167 (2017).

70. Tian, Y. et al. Mechanistic insights into perovskite photoluminescence enhancement: light curing with oxygen can boost yield thousandfold. Phys. Chem. Chem. Phys. 17, 24978-24987 (2015).

\section{Acknowledgements}

This work was supported by funding from the Energy Materials and Surface Sciences Unit of the Okinawa Institute of Science and Technology Graduate University, the OIST Proof of Concept (POC) Program, the OIST R\&D Cluster Research Program, and JSPS KAKENHI Grant Number JP18K05266. S.L. acknowledges the funding support from the 111 Project (B14041). The authors thank Dr. Mikas Remeika for writing the software for steady-state power measurements, Mr. Toshio Sasaki, Mr. Laszlo Szikszai and the Nanofab members for SEM characterization, Dr. Zhanhao Hu and Dr. Qijing Wang for insightful discussion for SCLC characterization.

\section{Author contributions}

Y.Q. supervised the project. Y.Q. and Z.L. conceived the ideas and designed the experiments. Z.L. conducted the corresponding device fabrication and basic characterization. L.Q. helped with $\mathrm{TiO}_{2}$ fabrication and stability study. E.J.J.-P. helped with EIS characterization, performed XRD cell parameter calibration, and TRPL fitting. Z.H. performed the conductive AFM characterization. T.K. and Z.H. performed SIMS characterization. Y.J. helped with module fabrication. Z.W. helped with mesoporous $\mathrm{TiO}_{2}$ fabrication. S.R.R. and L.K.O. helped with $\mathrm{CH}_{3} \mathrm{NH}_{2}$ gas reaction system setup. S.L. provided valuable suggestions for this work. Z.L. and Y.Q. participated in all the data analysis. All authors contributed to writing the paper.

\section{Additional information}

Supplementary Information accompanies this paper at https://doi.org/10.1038/s41467018-06317-8.

Competing interests: The authors declare no competing interests.

Reprints and permission information is available online at http://npg.nature.com/ reprintsandpermissions/

Publisher's note: Springer Nature remains neutral with regard to jurisdictional claims in published maps and institutional affiliations.

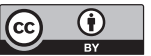

Open Access This article is licensed under a Creative Commons Attribution 4.0 International License, which permits use, sharing, adaptation, distribution and reproduction in any medium or format, as long as you give appropriate credit to the original author(s) and the source, provide a link to the Creative Commons license, and indicate if changes were made. The images or other third party material in this article are included in the article's Creative Commons license, unless indicated otherwise in a credit line to the material. If material is not included in the article's Creative Commons license and your intended use is not permitted by statutory regulation or exceeds the permitted use, you will need to obtain permission directly from the copyright holder. To view a copy of this license, visit http://creativecommons.org/ licenses/by/4.0/.

(c) The Author(s) 2018 